\title{
EL REY BURLADO: \\ DEUDA PÚBLICA Y FISCALIDAD EN EL REINO DE MALLORCA (SIGLO XV)
}

\author{
THE DECEIVED KING: \\ NATIONAL DEBT AND FISCALITY IN THE KINGDOM OF MAJORCA \\ (15th CENTURY)
}

PAu CATEURA BENNÀSSER Universitat de les Illes Balears

\begin{abstract}
Resumen: A partir de 1350 se produce la crisis del sistema fiscal vigente: derrama de impuestos para destinar a capítulos de gasto, señalados por la Corona. La magnitud de las peticiones de subsidios provoca la aparición de la deuda pública. La consecuencia de las bancarrotas municipales de 1372 y de 1405 fue la alienación de los recursos fiscales a favor de los acreedores.
\end{abstract}

Palabras clave: Corona; Deuda pública; Fiscalidad.

\begin{abstract}
From 1350 the crisis of the effective fiscal system takes place: spill of taxes to destine to cost chapters, indicated by the Crown. The magnitude of requests of subsidies causes the appearance of the national debt. The consequence of the municipal bankruptcies of 1372 and 1405 was the alienation of the fiscal resources in favor of the creditors.
\end{abstract}

Keywords: Crown; National debt; Fiscality.

\section{SUMARIO}

1. Introducción.- 2. La organización fiscal y financiera.- 3. El impuesto público al servicio del crédito privado.- 4. Adaptaciones fiscales.- 5. El rendimiento de los impuestos indirectos.

\section{INTRODUCCIÓN}

Desde 1300 y a lo largo de casi todo el siglo XIV, los impuestos indirectos municipales tienen por objeto alimentar los subsidios concedidos a la Corona y programas propios de defensa. Las guerras del siglo XIV provocan una expansión del sistema fiscal indirecto, hasta alcanzar la treintena de imposiciones. Pero desde mediados del siglo aludido empieza a modificarse la instrumentación de los impuestos indirectos, al introducirse la deuda pública. El abono de los intereses de la mencionada deuda introduce un capítulo fijo y creciente en las haciendas municipales de las islas.

En un proceso que se extiende entre 1377 y 1405 se produce un enajenamiento de los recursos fiscales indirectos de Mallorca a favor de los acreedores de la deuda pública, que se completa en la última fecha indicada. 
En Menorca se produce el mismo fenómeno, aunque de forma más tardía, en 1439. Ibiza parece escapar al proceso de enajenamiento de los impuestos indirectos, al menos en la medida de las islas mencionadas.

En suma, el sistema fiscal indirecto vigente en el siglo XV ha adquirido un sentido y un objetivo muy diferentes a los de su creación un siglo antes: si surgieron para alimentar los subsidios a la Corona, ahora alimentan en exclusiva los intereses de los créditos, a largo plazo, de los particulares. Éstos últimos, a través del sistema de subasta anual de los impuestos indirectos, se benefician también de su arrendamiento.

La malla de impuestos indirectos registra algunas novedades, en el contexto de convulsiones sociales (asalto a la judería en 1391 y revuelta campesina de 1450) se imponen nuevos tributos, alguno de los cuales acabó siendo abolido. Mayor fortuna tuvieron los afitons o recargos, destinados en principio, a dar continuidad al sistema fiscal indirecto bajo control del municipio, durante cierto tiempo.

\section{LA ORGANIZACIÓN FISCAL Y FINANCIERA}

Al filo de 1400, el reino de Mallorca se configuraba en 3 organismos:

a) El Consell General de Mallorca, donde se integraba el brazo de los foráneos (Sindicato Foráneo).

b) El Consell General de Menorca.

c) El Consell General de Ibiza.

Los Consells Generals de las islas constituyen su máxima expresión institucional. Desde la primera mitad del siglo XIV, con la consolidación de 32 municipios en el interior de Mallorca, se estructura un sistema complejo de ámbitos y competencias fiscales. Si tenemos en cuenta el criterio de niveles tributarios podemos establecer la siguiente clasificación:

a) Nivel local: se trata de la fiscalidad interna que afecta a los 38 municipios insulares. Los municipios rurales, tanto en Mallorca (32 entidades) como en Menorca (3 municipios), tienen una fiscalidad propia, basada en los impuestos directos, para atender gastos propios. Un caso aparte es el de Ibiza, con un solo municipio.

b) Nivel supralocal: desde 1315 los 32 núcleos rurales de la isla de Mallorca aparecen agrupados en un organismo propio, denominado Consell del Sindicat, donde se integran los 10 síndicos (de ellos dos clavarios). Este Consell está autorizado para derramar entre las villas afectadas impuestos directos con la finalidad de subvencionar algún gasto común -caso por ejemplo de remisión de síndicos a la Corte-, así como distribuir entre las villas el producto de un fondo común, entre ciudad y parte foránea, destinado a obras públicas.

El Sindicato tiene por función repartir entre las villas la cuota en los impuestos directos derramados en toda la isla, siguiendo la proporción establecida en 1315, por la sentencia arbitral de Sancho de Mallorca. Según este documento, vigente durante toda la Edad Media, la carga impositiva 
insular debía dividirse en tres partes: $2 / 3$ a cargo de la capital de la isla, y $1 / 3$ el interior de la misma. La opción prioritaria de los impuestos indirectos, durante todo el siglo XIV, permitió soslayar dicha proporcionalidad, pero a partir de 1405, cuando todos los impuestos indirectos fueron consignados al pago de los intereses de la deuda pública, el impuesto directo quedó casi como la única opción para conseguir recursos. Es entonces cuando el Consell del Sindicat reclama la operatividad de la proporción indicada. En 1423, existió el proyecto de imponer en toda la isla una talla o impuesto sobre el patrimonio a sou e liura, con independencia de dicha proporcionalidad. El proyecto no fue adelante por la cerrada oposición de dicho organismo, que reclamaba la aplicación estricta de dicha proporcionalidad. En suma, si la talla que se quería imponer, por valor de 25.000 libras, se derramaba según lo dispuesto en el documento de 1315, 16.666,6 libras debían repartirse entre los vecinos de la ciudad, y 8.333,3 libras entre los habitantes del interior de la isla. Si se imponía la talla, según el patrimonio de cada vecino, los habitantes del interior de la isla acabarían contribuyendo en mayor medida. En aquella fechas, la capital de Mallorca tenía casi 14.000 vecinos y el interior de la isla poco menos de 29.000 habitantes $^{1}$.

Esta organización de los núcleos rurales en una entidad propia es algo específico de Mallorca. Ni Menorca ni Ibiza cuentan con una organización similar representativa de los intereses rurales. Los vecinos de Mahón, por ejemplo, pueden enviar un síndico a la Corte, pero éste tendrá una representación limitada a la villa de origen ${ }^{2}$. En Ibiza, solamente en 1369 se contempló la presencia estatutaria, en el Consell General de 50 miembros, que preceptivamente debía integrar una representación de 17 miembros extra menia. Pero esta representación campesina en Ibiza no tenía personalidad propia, fuera de su participación en el Consell General de dicha isla.

c) Nivel insular: las decisiones, en materia fiscal, que afectaban a cada una de las islas se tomaban en sus respectivos Consells Generals (en Menorca e Ibiza desde la segunda mitad del siglo XIV).

La complejidad del sistema administrativo de Mallorca determinó que los tres consells involucrados - Consell de la Ciutat, Consell del Sindicat y Consell General- tuvieran que establecer un catálogo de gastos concernientes a cada una de las entidades, lo cual no resultaba fácil.

En principio, en el capítulo de gastos generales bajo jurisdicción del Consell General se encontraban la defensa y vigilancia de la isla, la importación de alimentos, y las embajadas como factores más destacados. Como segundo renglón, las peticiones de subsidios por la Corona. Como gastos específicos del Consell de la Ciutat y del Consell del Sindicat los

${ }^{1} \mathrm{~F}$. SEVILlano Colom, La demografía de Mallorca a través del impuesto del morabatí (siglos XIV-XV) "BSAL", 34 (1974), p. 248; A. SANTAMARÍA, El reino de Mallorca en la primera mitad del siglo XV, Palma de Mallorca, 1955, pp. 93-95.

${ }^{2}$ Excepcionalmente, se enviaron síndicos a la Corte con una representación de carácter popular. En 1377, consta la embajada de B. Muntaner, "síndich e procurador del popular e ma menor de la dita illa de Manorcha" (ACA, C, reg. 1436, fol.s. 92 v. -95 r.). 
concernientes a obras públicas y de infraestructura y embajadas particulares a la Corte, aunque en la práctica las obras de defensa en la ciudad fueron consideradas obras de utilidad general y por consiguiente dependientes del Consell General.

Todo ello acabó concretándose, en el establecimiento de una plantilla para las embajadas generales, integradas por tres miembros, dos de la ciudad y uno de la parte foránea. A partir de 1373, cuando la monarquía impuso un recorte de gastos generales del reino, se limitó a un solo síndico las embajadas ordinarias, introduciéndose entonces un sistema rotativo.

El control del municipio por la Corona no era ningún secreto desde 1343, el rey, a través de los gobernadores, designa a los Jurados y vigila la designación de los consejeros, tiene la autoridad para autorizar o no la derrama de impuestos u otras modalidades de ingreso, así como la prórroga de los impuestos vigentes, el rey finalmente puede modificar el sistema electoral, la composición del Consell General e incluso saltarse las fechas preceptivas de renovación de los cargos y representaciones ${ }^{3}$.

La monarquía no puede, por sí misma, señalar una necesidad, y a continuación derramar impuestos, gestionarlos y recaudarlos. a través de sus propios agentes, marginando al Consell General. Esta asamblea representa, aunque sea de forma imperfecta, al reino de Mallorca. Por otra parte, esta asamblea, carece de "soberanía" o facultad de imponer tributos, facultad que reside en el rey ${ }^{4}$. La relación entre ambas instituciones es entonces fruto de un punto de encuentro: en el rey reside la facultad de autorizar los tributos, en el Consell General la facultad de gestionarlos y recaudarlos.

Siempre que se tratara de subsidios generales del reino de Mallorca era el Consell General quien organizaba y gestionaba todo el aparato financiero. Esto significaba una centralización, a través de los órganos generados por la propia institución - como los clavarios y banca municipalde todas las fases que culminaban en el ingreso y rendición de cuentas tanto de los impuestos directos como indirectos, tanto por subsidios a la Corona como derramas generales para la importación de grano o defensa de la isla.

El Consell General de Menorca tenía problemas similares a los de Mallorca. La agenda de temas generales de la isla, defensa y abastecimiento, subsidios a la Corona eran competencia de su Consell General. Desde mediados del siglo XIV, el problema principal era evidentemente el de la defensa. Una isla con un perímetro de costa de 216 kilómetros, habitada por unos 4.000 habitantes y 13 caballeros no parecía lo más adecuado para atender una defensa en tiempo de guerra.

${ }^{3}$ El mandato de los Jurados y de los consejeros era anual, renovándose el 24 de diciembre. Sin embargo, el 14 de agosto de 1387 fueron elegidos Jurados y Consell General, de acuerdo con un nuevo régimen establecido por el rey Juan 1 , en lugar de esperar al 24 de diciembre que era la fecha tradicional. Años después, en 1398, el virrey Huc d' Anglesola renovó los Jurados del reino en 18 de mayo, en aplicación de una nueva pragmática que implantaba la rotación de parroquias urbanas en el Consell General.

${ }^{4}$ En 1327, el regente Infante Felipe establecía que "nulla fieret colecta in insula Maioricarum per modum tallie, questie nec aliter nisi de consensu regio atque nostro, nec ajuta vini”. 
Frente a esta situación, se prohibió la emigración de menorquines a Cerdeña, fue renovada la obligatoriedad de Mallorca de enviar socorros suficientes a Menorca, en caso de peligro, y correr con los gastos. Finalmente, el rey promovió la defensa de Ciudadela y de Mahón. En el siglo XV se difunden políticas de atracción de pobladores 5 .

El problema de Ibiza no era sólo de penuria de medios, sino de falta de coordinación entre las distintas administraciones involucradas: la administración real y la administración eclesiástica de la Mitra de Tarragona. El problema de esta isla es que resultaba indefendible por sí misma: contaba con una población en 1329, único recuento del siglo XIV, en torno a los 2500 habitantes, 16 hombres a caballo y 238 kilómetros de costa entre Ibiza y Formentera, además de numerosos esclavos. En 1503, la población de la isla ascendía a poco más de 4000 habitantes.

d) Tributación conjunta de las islas.

La tributación conjunta de las islas tiene su origen en la concesión de subsidios a la Corona. Desde principios del siglo XIV, el Consell de Mallorca ofrecía dichos subsidios en nombre de las demás islas. Las imposiciones adscritas a su financiación, así como su gestión y recaudación corrían a cuenta de los organismos dependientes del Consell de Mallorca.

Pero a partir de las guerras de Génova y de Castilla, el reino de Mallorca quedó comprometido en las grandes operaciones de la época a través de sucesivos dones y subsidios. El solapamiento de unos y otros y su intensidad determinaron fuertes tensiones entre los Jurados y Consell de Mallorca, por dirigir y coordinar todo el movimiento fiscal del archipiélago, y los Jurados y Consells de las demás islas, especialmente de Menorca, por soslayar el dirigismo de Mallorca y alcanzar cierta autonomía en la gestión de sus recursos.

El Consell General de Mallorca negociaba la cantidad del subsidio, siempre en nombre de todo el archipiélago, y los impuestos asignados a su financiación, corriendo a su cargo el arrendamiento de los tributos y su recaudación. El gobernador de Mallorca, en nombre de los Jurados y Consell de Mallorca, comunicaba a los Jurados de las islas menores lo acordado, exigiéndoles su colaboración en todo el proceso de arrendamiento-recaudación que agentes, desde Mallorca, realizarían en sus respectivas islas. Este sistema tenía las ventajas derivadas de la homogeneidad de la fiscalidad en todo el archipiélago y de su propia eficacia. Pero tenía dos graves defectos: el principio del quod omnes tangit y las mismas especificidades económicas de las islas menores. La marginación de las autoridades municipales de Menorca e Ibiza en las deliberaciones del Consell General de Mallorca sobre la concesión de subsidios y su financiación era sentido como un agravio comparativo por las autoridades municipales de las islas menores. Eran llamados a contribuir, pero no convocados a deliberar.

${ }^{5}$ A.M. ARAGó; R. CONDE, Llibre Vermell de Ciutadella, Barcelona, 1977, p. 168, doc. 426. 
En 1367, el rey intentó zanjar definitivamente la cuestión buscando una vía objetiva que permitiera establecer la proporcionalidad de la contribución respectiva del complejo insular. El sistema se basaba en la misma técnica que se utilizaba para establecer las cuotas de contribución en los impuestos directos: el manifest o declaración de bienes por los interesados. La decisión real, con rango de pragmática, establecía un comité de 14 personas, 10 de Mallorca y 4 de Menorca, quienes debían establecer una metodología de trabajo encaminada a conocer el valor de los bienes de todos los habitantes de las respectivas islas. A partir de ahí, pasar a la segunda fase consistente en trasladar la proporcionalidad de valoraciones globales de bienes a nivel insular a una proporcionalidad fiscal, derivada de la primera, proporcionalidad que sería constituida en la base futura de contribución respectiva en los dones y subsidios conjuntos.

Finalmente, cada isla tendría plena autonomía en la derrama y recaudación de impuestos. Las reuniones bilaterales sólo se impondrían cuando el rey solicitara un don al reino de Mallorca, con carácter general, y para aquilatar si cada isla había cubierto su cuota proporcional en el subsidio.

La opción de base escogida por el rey, la declaración y valoración de bienes, debió ser sugerida por las partes. Consta, por ejemplo, que en 1360, es decir sólo 7 años antes de la mencionada pragmática real, los Jurados de Mallorca habían ordenado la realización de un manifest de la valura des béns de les gents ${ }^{6}$ y que en 1358 se había realizado en Menorca un proceso igual ${ }^{7}$.

Todo ello debió hacer innecesaria la compleja maquinaria de expertos - de 14 miembros según expresaba el rey- y que ambas partes pactaran el nombramiento de árbitros. En efecto, al año siguiente, en 1368, dos delegados de los Jurados de Mallorca, junto con otros dos de los Jurados de Menorca y tres agentes reales, encabezados por el lugarteniente de gobernador de Mallorca, acordaron ajustar la contribución de Menorca en los subsidios vigentes en un 4,08\% ( una parte de cada 24,5) del total y Mallorca e Ibiza en el restante $95,92 \%$ y para los subsidios futuros en un 4,00\% (una parte de cada 25) y Mallorca e Ibiza en el $96,00 \%$ del total ${ }^{8}$.

Esta solución, adoptada finalmente por los mismos interesados, cerraba una etapa de conflictos sobre la cuota de contribución conjunta.

Por otra parte, la mencionada pragmática consagraba la "autonomía" fiscal de cada isla. Los impuestos adscritos al pago de los subsidios conjuntos deberían ser negociados entre las respectivas universidades y la Corona, corriendo a cargo de cada isla su gestión, recaudación y la inversión en las finalidades señaladas en la concesión del subsidio. La virtud de la pragmática de 1367 es la de mantener un vínculo fiscal interinsular, al conservar la presencia reglamentaria de síndicos de Menorca en las peticiones de subsidios

${ }^{6}$ ARM, AH, L.C. 22 , fol. 209 v.

${ }^{7} \mathrm{ARM}, \mathrm{AH}, \mathrm{L}$. C. 20, fol. 75 y. Para ello el Consell General de Menorca designó a 4 delegados para "reebre les denunciacions de la valor dels béns dels habitadors en la dita illa".

${ }^{8}$ A. ARAGÓ; R. CONDE, Llibre Vermell, cit., p. 104. 
generales realizados por la Corona y en la siguiente deliberación, así como en las reuniones bilaterales para aquilatar y colmatar el porcentaje respectivo de contribución. Por otra parte, una modesta cuota reglamentaria del $4 \%$ de contribución, por parte de Menorca, determinaba una base objetiva de partida, fuese cual fuese el montante del subsidio concedido al monarca, aunque este último hizo valer la cláusula de peticiones separadas de subsidios a cada isla.

La relación con Ibiza, en el tema de la contribución conjunta, discurrió por caminos diferentes debido a las circunstancias. Hasta 1359, tanto si se trataba de dones ofrecidos a la Corona como de temas de defensa del archipiélago, los Jurados de Mallorca negociaban con los de Ibiza la cantidad que éstos últimos aportarían, que solía oscilar entre 10.000 y 14.000 sueldos, y la trama de impuestos asignados. Agentes de los Jurados de Mallorca cuidaban de los arrendamientos de los tributos y de su recaudación.

En 1367, con motivo de la publicación de la mencionada pragmática que estableció la contribución conjunta de Mallorca y Menorca sobre la base de la previa valoración de bienes, no estuvo ningún síndico de Ibiza y sí en cambio dos síndicos de Mallorca y uno de Menorca. Tampoco figura entre los firmantes el arzobispo de Tarragona o el pavorde de la misma, que eran partes interesadas. Es importante señalar esto, porque el mencionado documento aludía a la contribución de Ibiza, de acuerdo con el mismo sistema de valoración de bienes que las demás islas.

El tema de la contribución conjunta de Mallorca e Ibiza quedaba entonces abierto a una negociación bilateral para fijar la cuota respectiva. Pero así como un arbitraje, realizado en 1368, ponderó en un 4\% la contribución de Menorca, no consta un acuerdo similar respecto a la contribución de Ibiza. Ante esta situación, es posible pensar que Ibiza se adhiriera a la misma cuota alcanzada por Menorca o sencillamente, al no haber denunciado el sistema tradicional de contribución conjunta, como había hecho Menorca, siguiera contribuyendo en los mismos términos.

En cualquier caso, desde la década de 1350 , tal como señala $\mathrm{J}$. Morelló, los representantes de Ibiza negociaban ya directamente con la Corona la concesión de imposiciones y los plazos de vigencia ${ }^{9}$.

El tema de la organización de la contribución interinsular, estimulada por la presión financiera de la monarquía, acabó desembocando en un sistema asimétrico: existe un convenio bilateral firmado, en 1368, entre Menorca y Mallorca e Ibiza, por el que Menorca contribuye en los subsidios generales en un $4 \%$ del total de acuerdo con los principios de la pragmática del año anterior; en cuanto a la contribución individualizada de Ibiza no consta una relación estatutaria similar.

En suma, podemos indicar que a partir de 1367 se establece un modelo de contribución conjunta, que terminaba con los contenciosos de épocas anteriores, aunque muy raras veces se produjo tal tipo de contribución.

${ }^{9} \mathrm{~J}$. MORELLó, El mercat de les imposicions a Eivissa: els arrendaments, a Comprar, vendre i pagar al rei (Els impostos indirectes a la Corona d'Aragó $i$ regne de Mallorca, segles XIV-XV), en prensa. Agradezco al autor las facilidades dadas para la consulta del trabajo. 
De hecho, cada isla pasó a conceder subsidios separadamente y a negociar las condiciones de las imposiciones.

\section{El IMPUESTO PÚBLICO AL SERVICIO DEL CRÉDITO PRIVADO}

En Mallorca se hace un recorrido bastante rápido entre las primeras emisiones de deuda pública, en 1355, y la consignación de todos los impuestos indirectos al pago de intereses de la deuda, en 1405.

\begin{tabular}{|l|l|l|}
\hline Año & Pensiones anuales & $\begin{array}{l}\text { Capitales invertidos en } \\
\text { deuda pública }\end{array}$ \\
\hline 1355 & 40.000 sueldos & 400.000 sueldos \\
\hline 1362 & 100.000 sueldos & 1.000 .000 sueldos \\
\hline 1372 & 416.420 sueldos & 4.164 .200 sueldos $^{10}$ \\
\hline 1377 & 500.000 sueldos & - \\
\hline
\end{tabular}

En 1377 se consignaron 8 impuestos indirectos al pago de la deuda. Los ingresos fiscales no vinculados oscilaban entre un $20 \%$ y un $30 \%$, dependiendo de las anualidades.

Finalmente, en 1405, ante los atrasos en el pago de los intereses, la presión realizada por los acreedores (mallorquines y catalanes), determinó la consignación de todos los impuestos indirectos al pago de las pensiones de la deuda pública ${ }^{11}$.

Lo significativo de este último período es que si durante la primera mitad del siglo XIV la estrategia consistió en ampliar el abanico de los impuestos indirectos y en el retoque al alza de las tarifas, ahora se cruzan dos líneas: se emite nueva deuda pública contra impuestos indirectos ab initio no vinculados ( los afitons) o contra impuestos directos y se emite deuda pública, a menor interés, para amortizar deuda pública a mayor interés.

El siglo XV, se abre bajo la perspectiva indicada de la consignación de todos los impuestos indirectos al pago de la deuda pública. Por ironías de la historia, el impuesto directo pasa a ser la única alternativa fiscal para

${ }^{10} \mathrm{P}$. CATEURA BENNÀsSER, La trentena esgarrifadora (Guerra i fiscalitat, el regne de Mallorca, 1330-1357, Palma, 2000, pp. 97-100; Ídem, Sociedad y sistema fiscal del reino de Mallorca (1360-1400), Palma, 2003, pp. 170-175.

${ }^{11}$ De hecho, a raíz de la revuelta social de 1391 con el asalto al Call o judería de la capital de Mallorca y abolición de las imposiciones, Juan I concedió a la Universidad de Mallorca la restauración del sistema fiscal con el objeto de pagar las pensiones de deuda pública, otorgando al Consell General "plenam potestatem" para aumentar o disminuir las imposiciones y administrarlas "sine aliquo regiorum officialium interventu" (ARM, Llibre de Sant Pere, fol. 146v.). 
conseguir recursos. Digo ironías de la historia porque las clases dominantes habían rechazado esta fórmula durante todo el siglo XIV.

Durante el siglo XV se perfilan tres grandes etapas:

A) Período de 1405-1460: Es la época de introducción de nuevos impuestos directos, como el subsidi (por importe anual de 200.000 sueldos) o la subvenció (por importe de 40.000 sueldos) y sobre todo la misma gabela de la sal, creada en 1425. Por otra parte, los impuestos indirectos sufren un proceso de duplicación, siempre que contara con el consentimiento de los acreedores censalistas: son los llamados afitons o sobretasas sobre la carne, paños, molienda (este último tuvo que ser retirado, en 1418, ante las protestas de los campesinos). Durante este período se registran tres iniciativas: dos de tipo fiscal, con el proyecto de creación de un impuesto único de tipo directo, en 1440, y la imposición del Dret del General, en 1454, y la reconversión de la deuda exterior en interior. La primera iniciativa fracasó y la segunda y la tercera consiguieron un éxito limitado ${ }^{12}$.

B) Período de 1461-1479: Es la época de la guerra civil catalana cuando el rey Juan II toma la medida de confiscar todas las pensiones de deuda pública en manos de "rebeldes" catalanes. Si a partir de la consignación de todos los impuestos indirectos, la monarquía había sido marginada en parte del botín fiscal, ahora se convierte en beneficiaria de una parte del mencionado botín, porque incluso fuerza la amortización de título de deuda.

C) Período de 1479-1516: es el período de reformas inspirado por Fernando el Católico. De este período destacaré dos aspectos: una nueva oleada de afitons sobre paños, vino y vectigal de la mercadería y un aspecto nuevo, la gestión directa de algunos impuestos indirectos por la administración en la ciudad y de todos los percibidos en el interior de la isla (año 1490). La monarquía decide golpear a la oligarquía en uno de los puntos sensibles (las sociedades de arrendamiento de impuestos) al disponer la administración directa primero, en el período de 1488-1489, de algunos impuestos indirectos, y después, a partir de 1491 de prácticamente todos. Mallorca:

La evolución financiera y fiscal de Menorca es similar a la de

a) Hasta 1439: Durante este período la Corona autoriza las imposiciones y su prórroga, por períodos de 3 a 6 años, y también establece los límites del endeudamiento censal ${ }^{13}$. Pero esta línea se interrumpe en 1434 cuando Alfonso el Magnánimo da autorización a la Universidad de Menorca para imponer "impositiones sive sisas in omnibus victualibus, rebus et mercibus

\footnotetext{
${ }^{12}$ ARM, AH-3, fol. 93 v. En 1431, el $55 \%$ de la deuda era exterior, ascendiendo a 24.252 libras los intereses anuales que se abonaban a acreedores del Principado. Treinta años después, en 1463, el abono anual de intereses había descendido a 13.222 libras (R. URGELL, El regne de Mallorca a l'època de Joan II. La guerra civil catalana i les seves repercussions, Palma, 1997, p. 43 y J. MORELLó, Mallorca i la seva dependència financera del Principat (segles XIV-XV), "Anuario de Estudios Medievales", 33/1 (2003), p. 131.

${ }^{13}$ A.M. ARAGÓ; R. CONDE, Llibre Vermell de Ciutadella, cit., pp. 151, 157, 159 y 161.
} 
que inibi vendentur, ementur aut aliter contractabuntur" por un período de 30 años. En lo sucesivo no deberían rendir cuentas ante ningún oficial real ${ }^{14}$.

b) Período de 1439-1475: Pese a que la concesión de 1434 estaba destinada a resolver los problemas financieros de la Universidad de Mallorca, no parece que alcanzaran a lograr este fin, porque cinco años después una ordenanza de Alfonso el Magnánimo establecía que el clavario de la Universidad, al tomar posesión del cargo, debía jurar que pagaría los censales con cargo a las ayudas y que el remanente sería destinado a amortizaciones. Por ello, la consignación de los impuestos indirectos al pago de los censales es un hecho a partir de esta fecha. El impago de los intereses fue motivo para un nueva sentencia dictada por Juan II, en 1460, con condiciones más duras. Los Jurados, Consell General de Menorca y clavario, al tomar posesión del cargo, deberían jurar, ante el gobernador, que los ingresos procedentes de los impuestos indirectos debían destinarse exclusivamente al pago de censales y gastos ordinarios de la Universidad, pero éstos no debían sobrepasar las 500 libras ${ }^{15}$. El remanente debía ser dedicado a amortizaciones. El clavario propuesto por los acreedores del Principado debía ser elegido por los Jurados y Consell General de Menorca. Además se establecía un sistema de penalizaciones, 25 libras de multa a los Jurados en caso de perturbar la tarea del clavario, la misma cantidad al clavario por no cumplir su misión y los censales impagados, tras 5 meses de su vencimiento pagarían interés del $8 \%$. Se estableció también un plan de amortización de los censales atrasados, aunque no se menciona la malla de impuestos indirectos o el presumible establecimiento de afitons. En el documento se citan tres colectivos de acreedores: del Principado, de Mallorca y de la propia isla de Menorca, aunque no se otorga prioridad de pago a ninguno de ellos ${ }^{16}$. La guerra civil catalana provocó una división territorial de la isla, Mahón, controlada por la Generalitat, y Ciutadella, controlada por afectos al rey Juan II. Tal como había sucedido en Mallorca, el monarca pasó a confiscar los censales en manos de partidarios de la Generalitat. Sin embargo, la guerra provocó una acumulación de atrasos, que se intentó resolver a partir de 1475 .

c) $1475-1504$

Según cálculos realizados por los acreedores, los atrasos en el pago de censales, durante la guerra, ascendían a 19.358 libras, equivalentes a 5 anualidades del presupuesto de ingresos de la Universidad de Menorca. En circunstancias que desconocemos, en 1475 los Jurados y Consell de Menorca votaron la creación de afitons sobre las imposiciones vigentes y de un impuesto sobre el patrimonio, llamada subvenció, con un límite de 500 libras anuales. $\mathrm{Su}$ finalidad era que, una vez pagados los atrasos, serían abolidos. Al

\footnotetext{
${ }^{14}$ A.M. ARAGó; R. COṆE, Llibre Vermell de Ciutadella, cit., p. 170. El rey se hizo conceder 1000 florines por la mencionada disposición.

${ }^{15}$ Las embajadas no podían endosarse a la cuota de 500 libras de gastos ordinarios sino a otros ingresos de la Universidad de Menorca.

${ }^{16} \mathrm{~F}$. SASTRE, Algunas notas sobre la situación económica de las instituciones menorquinas en la primera mitad del siglo XVI, Menorca, 1989, pp. 13-16.
} 
año siguiente se desvelan nuevas condiciones: los nuevos impuestos serían administrados por Perot Pardo, como acreedor principal ${ }^{17}$ y representante de los acreedores, por un período de 19 años. En suma, el mencionado se hacía cargo tanto de los arrendamientos como de la recaudación y distribución entre los acreedores. La realidad fue que subarrendó a terceros la explotación de los mencionados impuestos, sin sacar los afitons a la preceptiva subasta anual. A partir de 1481, la Universidad de Menorca impugnó el contrato iniciándose una causa, con diferentes alternativas de embargo (durante casi 6 años) y desembargo de dichos impuestos, que todavía continuaba su hijo en $1504^{18}$.

En suma, durante el período indicado las imposiciones de Menorca estuvieron en manos de dos colectivos de acreedores: las llamadas imposicions majors vinculadas a un colectivo de acreedores del Principado, de Mallorca y de la propia isla. Los afitons y la subvenció vinculados a Perot Pardo, a la cabeza de un grupo de acreedores.

En Ibiza puede establecerse una cronología similar:

1) Entre 1403-1430, durante este periodo la monarquía exime de tener que rendir cuentas de su administración ante los delegados de la Corona ${ }^{19}$, pero desconocemos si la Mitra de Tarragona y el paborde actuaron en el mismo sentido. Por otra parte, según ha estudiado J. Morelló, un libro de clavaria municipal, de 1417-1418, califica las imposiciones como derechos ordinarios $^{20}$.

2) 1430-1500: el desarrollo de la deuda pública determina un vínculo con las imposiciones municipales. En la primera fecha señalada, el rey autoriza al municipio a establecer imposiciones sobre el pan, vino, carne y cualesquiera otros productos, sin límite temporal, siempre que su producto se destine a convertir en defensió, tuició e descàrrec dels deutes o censals, violaris e càrrechs de la dita illa ${ }^{21}$. La naturaleza y cuantía de las cargas censales del municipio de Ibiza se desconocen. En cualquier caso, no consta un proceso, como el de Mallorca y Menorca, de consignación de todas las imposiciones a los acreedores.

\section{ADAPTACIONES FISCALES}

Los hechos mencionados en el capítulo anterior determinaron que, desde mediados del siglo XIV, cada isla integrara una unidad fiscal diferencia-

\footnotetext{
17 “Que era hu dels majors crehedors" se dice en 1479.

${ }^{18} \mathrm{~F}$. SASTRE, Algunas notas sobre la situación económica, cit. pp. 40-46. Durante el período de 1476-1482 se calculaba que había ingresado poco más de 9.000 libras.

${ }^{19}$ La mencionada rendición de cuentas databa de 1261, cuando el infante Jaime concedió a los pobladores de la isla un millares para subvencionar obras de muros y otras comunitarias, pero sus representantes o prohombres debían rendir cuenta al rey o al "batle" real de las inversiones realizadas (A. FERRER, Les salines i la sal en el Llibre de la Cadena, 1261-1696, Eivissa, 2004, p. 20).

${ }^{20}$ J. MORELLÓ, El mercat de les imposicions a Eivissa, cit., pp. 16-18.

${ }^{21}$ Por dicha licencia el rey ingresó 2.400 florines.
} 
da, aunque con un sistema de impuestos indirectos prácticamente simétrico. Por otra parte, el tradicional permiso y prórroga de los impuestos indirectos, por la Corona, queda abolido desde el momento que dichos ingresos están consignados al pago de deuda pública.

De hecho, ya en 1390 la Universidad de Mallorca dispuso la compilación de un texto que reuniera todos los impuestos indirectos arrendados por la Universidad ${ }^{22}$ (que en adelante citaré como C29), realizándose una nueva compilación en el siglo XV con nuevas disposiciones ${ }^{23}$ (que citaré como C30). En Menorca se produce la consignación de impuestos al pago de la deuda a partir de 1439. Finalmente, en 1430, Alfonso V concedía a Ibiza el establecimiento de imposiciones sobre el pan, vino y carne y otras mercancías, sin límite temporal, para dedicar su producto al saneamiento financiero.La información más completa sobre los impuestos indirectos nos la proporciona Mallorca, seguida de Ibiza, que conserva registros de clavaria de 1417-1418, 1462-1474, 1500-1510, estudiados por J. Morelló, y Menorca, de la que sólo contamos con datos de ingresos fiscales indirectos para el período de 14761482 .

\section{Las imposiciones}

a) Imposiciones sobre artículos de primera necesidad:

\section{Cereales}

En Mallorca existían dos imposiciones sobre el grano, el llamado blat de la pera y la molitja o molienda a su vez dividida en dos, la molitja de la capital de la isla y la molitja del interior de la isla. El primero de ellos afectaba a la compraventa y consumo de cereales (trigo, avena, mijo, panizo, maíz y mestall mezcla de cereales o de cereales y legumbres). En el caso de la molienda, los habitantes de la ciudad pagan por quartera de grano molido. En el interior de la isla se aplicaron dos módulos: los panaderos, por quartera de grano molido tal como lo hacían los habitantes de la ciudad, y los particulares según grupos de edad, entre 5 y 10 años y a partir de 10 años pagaban una cantidad fija anual.

En 1390, las tarifas aplicadas al blat de la pera eran en relación con el precio, según tarifa unitaria de 2 dineros por libra, salvo los productores que sólo pagaban 1 dinero y los que compraban para consumo propio que quedaban exentos de pagar. En la primera mitad del siglo $\mathrm{XV}$, las tarifas fueron dobladas, según tarifa unitaria de 4 dineros por libra, salvo los productores 2 dineros por libra y los compradores para consumo propio que siguieron exentos ${ }^{24}$.

\footnotetext{
${ }^{22} \mathrm{ARM}$, Códice 29.

${ }^{23} \mathrm{ARM}$, Códice 30. Contiene adiciones que alcanzan al siglo XVII.

${ }^{24}$ ARM, Códice 30, fol. 95 r.
} 
En la molienda, las tarifas, de 1390, discriminan en función del tipo de cereal molido o harina comprada, distinguiendo dos grupos de contribuyentes, un primer grupo formado por los panaderos y patrones de naves, según tarifa unitaria, y los particulares. Los primeros pagan entre 13 dineros y 18 dineros por quartera, y los segundos entre 7 y 9 dineros. En la molienda del interior de la isla, los niños entre 5 y 10 años pagan entre 15 dineros y 27 dineros, y los mayores de 10 años entre 31 dineros y 54 dineros, finalmente los panaderos pagan lo mismo que sus homónimos en la ciudad. En la primera mitad del siglo $\mathrm{XV}$ todas las tarifas mencionadas fueron revisadas al alza, de forma que panaderos y patrones de naves pagan, según el tipo de cereal, entre 27 dineros y 36 dineros; los particulares, por su parte pasan a pagar entre 9 y 12 dineros por quartera ${ }^{25}$. No dispongo de las tarifas de la molienda en el interior de la isla, pero una declaración efectuada en torno a 1430, señalaba, de forma genérica que los habitantes pagaban 90 dineros por persona y año ${ }^{26}$.

\section{Vino}

El vino resulta el producto de mayor rendimiento fiscal en Mallorca $\mathrm{y}$, en menor medida en Menorca e Ibiza. Sobre el vino gravitan tres imposiciones, el sisé del vi y la imposició del vi e vinagre sobre las compraventas y el consumo, y el florí per bota sobre la circulación.

El más significativo es el primero mencionado. Como su nombre indica se trata de un impuesto calculado sobre el precio, que gravaba tanto a productores como compradores y revendedores. Es un impuesto universal del que están exentos, en parte, los clérigos y los caballeros; pero los primeros sólo en el caso de que el vino proceda de diezmos o beneficios eclesiásticos y los segundos sólo por sus caballerías o feudos antiguos ${ }^{27}$. Las compras para consumo propio también estaban exentas de pagar imposición. Según que las operaciones fueran al por mayor o al por menor se utilizaban diferentes medidas, el quarter major o el quarter menor, en el primer caso el impuesto debía asumirlo el comprador y en el segundo caso el vendedor.

En la segunda mitad del siglo XIV la tarifa era del 16,6 por ciento del valor del vino, porcentaje que fue elevado al 20 por ciento en la primera década del siglo XV.

La revisión de tarifas sobre el vino obedeció seguramente al privilegio concedido por Juan I, en 1395, a la villa de Alcudia, que centralizaba una de las comarcas vitivinícolas de la isla. Con la finalidad de mejorar la comercialización del diezmo de vino, el rey dispensó a dicha villa de pagar el sisé del $v i$ y de cualquier otra imposición municipal sobre este producto. Pese a que la Universidad de Mallorca recurrió la decisión real, ésta acabó consolidándo-

\footnotetext{
${ }^{25}$ ARM, Códice 30, fol. 104 r.

${ }^{26}$ J. JUAN VIDAL, La problemática de los censales: su incidencia en las Germanías (15211523), "Mayurqa", 13 (1975), pp. 148-150.

${ }^{27} \mathrm{~A}$. MAYOL, El vi en el sistema tributari de Mallorca (segles XIV-XV), "Mayurqa", 26 (2000), pp. 161-179.
} 
se. Según mis cálculos, la decisión real supuso una mengua de ingresos fiscales en torno al $6 \%$.

\section{Carne}

Desde sus inicios, a principios del siglo XIV, la imposición de la carne se relaciona con el peso, no con el precio. Con el fin de aminorar las repercusiones injustas de este sistema, las ordenanzas municipales establecían una escala de imposiciones, según la cualidad de la carne, desde las carnes más tiernas (ternero de leche), pasando por las carnes más utilizadas y finalizando por las de menos calidad, por ser animales viejos (cabra, oveja, boc) o enfermos. En cualquier caso, la escala de tarifas era muy limitada en 1390: 6 dineros por libra de peso, 4 dineros y 3 dineros $^{28}$. Estas tarifas fueron revisadas y diversificadas al alza, en el siglo $\mathrm{XV}$, tal como nos manifiesta el C30: 9 dineros, 7 dineros, 6 dineros, 5 dineros y 4 dineros por libra, aunque la mayor parte de las carnes se encuentran en la banda de los 5-6 dineros por libra ${ }^{29}$.

Esta imposición, denominada en la primera mitad del siglo XIV ayuda de las carnicerías y después ayuda de las carnes, debían abonarla los vendedores, es decir, los carniceros en el momento de vender el producto a particulares, aunque también afectaba a las operaciones realizadas entre los carniceros (entonces debía pagar el comprador).Como un impuesto independiente de la carne, aunque vinculado al mismo, se encuentra la imposició de la graxa, que gravaba dos tipos de productos, los alimentarios como el tocino, sebo, manteca, miel y los de tipo utilitario, como candelas de sebo. En 1390, una única tarifa establecía que los vendedores, si era de su cosecha, pagaban un dinero por libra, y los compradores dos dineros por libra ${ }^{30}$. El impuesto, en la primera mitad del siglo $\mathrm{XV}$, fue doblado.

\section{Pescado}

La imposición sobre el pescado (pescado fresco y salado) fue creada en 1331, aunque en 1360 adquirió su perfil definitivo al establecerse, a imitación de la carne, las tarifas en relación a una unidad de peso, la libra. El impuesto era repercutido tanto sobre el vendedor como sobre el comprador. En 1390, la tarifa era de 2 dineros por libra aplicada a cada una de las partes, con independencia de la calidad del pescado ${ }^{31}$. En el siglo XV, la tarifa fue

\footnotetext{
${ }^{28} \mathrm{ARM}, \mathrm{C} 29$, fol. $197 \mathrm{r}$.

${ }^{29}$ ARM, C30, fol. 120.

${ }^{30} \mathrm{ARM}, \mathrm{C} 29$, fol. $34 \mathrm{v}$.

${ }^{31}$ ARM C29, fol. 55 r. El pescado de la "Albufera major" de Alcudia estaba exento de pagar imposición.
} 
doblada, de forma que comprador y vendedor debían abonar 4 dineros por libra $^{32}$, sin discriminar la calidad del pescado.

\section{Aceite}

Durante el siglo XIV un único impuesto gravaba el aceite, era la imposición de l' oli de la terra ${ }^{33}$. El sistema de tarifas, al igual que el vino, se establece en relación con el precio. En 1390, la modesta tarifa de 2 dineros por libra $(0,8 \%)$ se repercute por un igual a compradores y vendedores. Sin embargo, los productores que vendan su cosecha sólo pagan 1 dinero por libra. Por otra parte, las compras para consumo propio están exentas de impuesto $^{34}$. Siguiendo el curso de otros impuestos sobre la alimentación, durante la primera mitad del siglo XV fueron dobladas las tarifas anteriores, de forma que los productores pasan a pagar dos dineros por libra y los compradores 4 dineros por libra ${ }^{35}$.

A fines del siglo XIV o principios de la centuria siguiente fue creado un nuevo impuesto sobre el aceite, denominado general de l'oli o también victigal de l'oli ${ }^{36}$. Al igual que la imposición sobre el aceite, el general de l' oli establece sus tarifas en relación con el precio del producto. Los compradores de aceite, al por mayor, para revender o para consumo propio estaban sujetos al impuesto del 12 dineros por libra (5\%), lo mismo que los exportadores, por otra parte, los productores y rentistas debían abonar 6 dineros por libra por cada miembro de su familia, con una edad superior a los ocho años, lo cual parece asimilarse a los principios que rigen la molienda del interior de la isla. En cualquier caso, esta última disposición fue abolida en $1468^{37}$.

\section{Frutos secos}

Entre las imposiciones sobre productos alimentarios figura la llamada de fruita seca, que agrupaba tanto frutos secos, como legumbres y hortalizas. En 1390, el impuesto gravaba con dos dineros por libra respectivamente a comprador y vendedor, salvo que fueran de cosecha propia del vendedor (imposición de un dinero por libra) o para consumo propio del comprador (no

${ }^{32} \mathrm{ARM}, \mathrm{C} 30$, fol. 37 r. Se mantiene la situación privilegiada del pescado de la Albufera.

${ }^{33} \mathrm{El}$ impuesto había sido creado en 1328 .

${ }^{34}$ ARM, C29, fol. 66 r.

${ }^{35}$ ARM, C30, fol. 59 r.

${ }^{36}$ En el capítulo introductorio de este impuesto se indica como justificación "los honorables jurats de la Universitat del regna de Mallorques volents, per los càrrechs de la Universitat damunt dita, metra o posar collecta o general en l' oli qui.s comprará en Mallorques per qualsevol persones laiques o no privilegiades" (ARM, C30, fol. 74 r. ).

${ }^{37}$ Una declaración de los Jurados, en la fecha indicada, establecía que "los compradors del dit dret del dit capítol, quant és en lo cap dessús especificat, no degen ne puxen en alguna manera usar, ans degen seguir o observar lo ús e pràticha sobre açò acustumada" (ARM, C30, fol. 78 v.) 
pagaba imposición ${ }^{38}$. Siguiendo el criterio general, aplicado en la primera mitad del siglo XV, tales tarifas fueron dobladas.

Del análisis de las imposiciones sobre la alimentación se deducen dos grupos, el primero, integrado por la molienda, la carne y el pescado, con un formato socialmente injusto bien por establecer la tarifa con independencia del consumo (molienda del interior de la isla), bien por establecerla en relación con el peso, con una reducida y poco diversificada banda de tarifas en relación con la calidad de las carnes o pescados. Un segundo grupo, lo integran las imposiciones sobre el vino y el aceite con tarifas relacionadas con el precio de estos productos.

\section{b) Imposiciones sobre compraventas}

Figuran dentro de este grupo, un conjunto de quince imposiciones que gravan productos en bruto o manufacturados (textil, piel y cuero, madera y hierro, materiales de construcción $)^{39}$.

De entre todos ellos, la imposición más destacada es la ajuda del tall dels draps, que afectaba a la compraventa de paños $^{40}$. No cabe olvidar, según señala D. Abulafia, que desde finales del siglo XIV "no sólo Mallorca se convirtió en un próspero centro para la industria textil, cuya producción iba dirigida a la mitad superior del mercado, sino que además Menorca y en cierta medida también Mallorca se convirtió en una importante región productora de lana" ${ }^{41}$.

El impuesto afecta a las compraventas con una normativa muy detallada. En 1390 se establece una tarifa única sobre los vendedores de 15 dineros por libra, aceptándose desgravaciones en el caso de compraventa de vestiduras ${ }^{42}$. Del impuesto estaban exentos los clérigos.

En la primera década del siglo XV la tarifa sobre los paños fabricados en Mallorca fue aumentada a 18 dineros por libra y, en 1445, fue doblada hasta los 36 dineros por libra. En sintonía con la política proteccionista de la industria textil insular, en la mencionada centuria, los paños extrajeros de lana o seda fueron gravados con 72 dineros por libra ${ }^{43}$.

\footnotetext{
${ }^{38} \mathrm{ARM}, \mathrm{C} 29$, fol. $102 \mathrm{r}$.

${ }^{39}$ Ajuda dels draps,imposició de la llana, imposició de la fịlaza i barragans, imposició de la pedra, calç, botes, imposició ferro, imposició canyem, imposició subastes i payaria, imposició lli ị estopa, imposició dẹel bestiar, imposició del cuiram pelós, imposició espart i palma, imposició cuiram adobat, imposició exàrcia de cànyem, imposició pelleteria, imposició de la fusta.

${ }^{40}$ Los paños que se mencionan en la normativa eran "draps de lane, xamelots, veluts, draps d' or e de seda, sendats, fustanis, cordelats, amples o strets, sayes per obs de vestir" (ARM, C29, fol. $159 \mathrm{r}$ ).

${ }^{41} \mathrm{D}$. ABUlafiA, Un emporio mediterráneo. El reino catalán de Mallorca, Barcelona, 1996, p. 277.

${ }^{42}$ Los vendedores de "vestedures" debían abonar los 15 dineros por libra pero desgravaban 30 dineros por pieza en concepto de "avaries, traballs i costures" (ARM, C29, fol. 159 r).

${ }^{43}$ J. JUAN VIDAL, La problemática de los censales, pp. 148-150.
} 
c) Imposiciones sobre la circulación de personas y productos.

Dentro de este ámbito se encuentran tres imposiciones, a fines del siglo XIV, la de la taula de la mercaderia ${ }^{44}$, el florí per bota ${ }^{45}$ y la de entrada i exida de navilis ${ }^{46}$.repercutida respectivamente sobre comprador y vendedor. Exentos de la imposición están los compradores de grano para consumo propio. El florí per bota, impuesto creado en 1395, grava exclusivamente la importación y exportación de vino. Su tarifa de 20 sueldos se establece no en relación con el precio, como la imposición del sisé del vi sino con una unidad de capacidad, el tonel o bota. Finalmente, la imposición de entrada i exida de navilis gravaba todas las naves, cargadas o descargadas, en función de su procedencia o destino (se fijan once regiones comerciales en el Mediterráneo y en el Atlántico) y del tipo de embarcación. De esta regla era excluidas las embarcaciones venecianas que pagaban una cantidad fija por galera.

A fines del siglo XIV surge el victigal de la mercaderia, concebido como una imposición que grava todas las importaciones o exportaciones de productos, según una tarifa unitaria de 3 dineros por libra. De esta regla hay excepciones: el vino exportado de Alcudia no paga victigal ni tampoco los paños crudos, fabricados en Mallorca, pero por el contrario la exportación de la lana de la isla es gravada con siete dineros por libra ${ }^{47}$. Por otra parte, las tarifas del florí per bota fueron incrementadas, en el siglo XV, pasando de 15 sueldos a 20 sueldos por tonel, de ahí el nuevo nombre de reial per bota ${ }^{48}$.

La circulación de personas no aparece individualizada en la compilación de 1390. En la imposición de la taula de la mercaderia no aparece ningún capitulo referido a la importación o exportación de esclavos ${ }^{49}$. Sin embargo, en la imposición llamada de catius e censals, de la misma fecha, se fijan las compraventas de esclavos a dos dineros por libra $(0,8 \%)$, repercutidos respectivamente sobre vendedor y comprador ${ }^{50}$. Un anexo a la normativa sobre este impuesto, añadida en 1398, establecía la indemnidad de la administración municipal, respecto a la cuantía del impuesto arrendado, en el caso de rechazar el desembarco de esclavos, capturados por corsarios, en operaciones de mala guerra o cossaris ${ }^{51}$. En el siglo XV, consta que la compraventa de esclavos tenía un gravamen del $5 \%$.

${ }^{44} \mathrm{ARM}, \mathrm{C} 29$, fol. $165 \mathrm{r}$.

${ }^{45}$ J.F. LÓPEZ BONET, La revolta de 1391: efectivament crisi social, en XIII Congreso de Historia de la Corona de Aragón, Comunicaciones I, Palma, 1989, p. 119.

${ }^{46} \mathrm{ARM}, \mathrm{C} 29$, fol. $107 \mathrm{r}$. ; L1. TUDELA, L'origen de l'impost d'entrades $i$ exides de navilis a Ciutat de Mallorca, en Comprar, vendre i pagar al rei. Els impostos indirectes a la Corona d'Aragó $i$ Regne de Mallorca, s. XXIV-XV, 2005 (en prensa) pp. 15-21. Agradezco al autor las facilidades para consultar su trabajo.

${ }^{47}$ ARM, C30, fol. 49 r.

${ }^{48} \mathrm{ARM}, \mathrm{C} 30$, fol. $64 \mathrm{r}$.

${ }^{49}$ En dicha compilación se establece una tarifa general para la venta de productos importados de 2 dineros por libra (ARM, C29, fol. $165 \mathrm{r}$.).

${ }^{50} \mathrm{ARM}, \mathrm{C} 29$, fol. $48 \mathrm{r}$.

${ }^{51} \mathrm{ARM}$, C29, fol. $54 \mathrm{r}$. 
El mencionado victigal de la mercaderia, en la normativa de la primera mitad del siglo XV, establece ya un filtro fiscal de las importaciones y exportaciones de esclavos y las salidas de emigrantes. Las tarifas distinguen los esclavos menores de diez años y mayores de diez años, en el primer caso la tarifa es de 5 sueldos por persona, y en el segundo de 10 sueldos $^{52}$.

La crisis demográfica de la isla, en la primera mitad del siglo XV, determinó que mientras la inmigración era premiada con una subvención de 30 libras a cada emigrante y una franquicia de pago de determinados impuestos indirectos durante diez años, la emigración era penalizada. En efecto, todos los emigrantes debían abonar 31 dineros por libra $(12,9 \%)$ de todos los bienes que llevaran consigo ${ }^{53}$.

\section{d) Compraventa de rentas y capitales}

La filosofía de este impuesto es restrictiva, se grava exclusivamente la riqueza inmobiliaria y la renta en el momento en que circula, pero no la percepción de rentas. De ahí que de este impuesto escapan tanto las rentas agrarias como urbanas, los alquileres, los censales de deuda pública y las transmisiones inter vivos (donaciones) o testamentarias.

La mencionada imposición llamada catius e censals, es decir, de esclavos y rentas, esta últimas se presentaban bajo dos supuestos, la compraventa y la permuta. En el primer caso afectaba a bienes inmobiliarios y a rentas obtenidas en metálico y en especie, siempre que el precio se fijara en metálico. En el caso de las permutas, las tarifas contemplaban dos situaciones: la simétrica, es decir el concambio exclusivo de bienes o rentas, y aquella asimétrica, en la que una de las partes aportaba, para equilibrar la permuta, una cantidad suplementaria.

En 1390, las tarifas aplicadas son muy modestas. En el caso de compraventa de bienes o rentas el vendedor quedaba exento de pagar y el comprador debía abonar dos dineros por libra $(0,8 \%)$. En el caso de los concambios simétricos, comprador y vendedor debían abonar respectivamente un dinero por libra, y en el caso de las asimétricas, el vendedor pagaba un dinero y el comprador dos dineros por libra ${ }^{54}$. Estas tarifas fueron dobladas en el siglo XV, equiparándose la posición tributaria de cada una de las partes, compradores y vendedores pagan respectivamente 4 dineros por libra.

Las islas menores diseñan un sistema fiscal más simplificado, aunque simétrico con el de Mallorca. En Ibiza, según ha estudiado J. Morelló, existían en el siglo XV siete imposiciones: imposició de flaqueres, sisa del vino, sisa de la carne, imposición de los seis dineros por libra, tall dels draps, dret de catius, florí per bota y en 1440 se establece un victigal sobre las

\footnotetext{
${ }^{52}$ ARM, C30, fol. 50 v. De la norma estaban exceptuados los esclavos al servicio de su amo "que algun nadiu de Mallorques amen per son servei fora la illa, si dochs no.l venia la hon lo senyor lo amanas, que no sia més avant de hun catiu o bort”.

${ }^{53} \mathrm{ARM}, \mathrm{C} 30$, fol. 53r

${ }^{54}$ ARM, C29, fol. $47 \mathrm{v}$.
} 
mercancías descargadas, pero no puestas a la venta ${ }^{55}$. En Menorca, según tenemos documentado en 1476, constan las imposiciones sobre la carne, vino, paños, la imposició sobre los demás productos, y un victigal.

En Ibiza, la imposición de les flaqueres o panaderas afectaba a las compraventas de grano o harina, incluidos patrones de naves, según una tarifa establecida, en la segunda mitad del siglo XIV, de 48 dineros por quintal. Esta tarifa se mantuvo invariable durante todo el siglo XV. El sistema y la evolución de las tarifas sobre el vino en Ibiza era el mismo que en Mallorca, de forma que en el siglo XV, sin que podamos precisar el momento, pasó a imponerse el quint del vi. En Ibiza se ingresaba una sisa de la carne, pero desconocemos como era percibida. Solamente constan las tarifas de un afitó impuesto en 1440, en Ibiza, que examinaremos en su momento. Finalmente, el pescado era gravado con una tasa de 4 dineros por libra, a fines del siglo XIV. A diferencia de Mallorca, el impuesto sobre el pescado se aplica sobre el precio del producto.

Sobre el tráfico comercial de Ibiza, gravitaban las imposiciones llamadas dret de catius, sobre la entrada y salida de esclavos, tasada en 10 sueldos por persona, la imposició dels sis diners per lliura, se trata de una imposición generalista, dentro de la que se incluía por ejemplo la compraventa de fincas y rentas (gravada con tres dineros por libra) y el impuesto florí per bota sobre la importación y exportación de vino.

En Menorca, consta la imposición de sisas sobre el pan, vino y carne desde antes de 1366, pero no se conserva el sistema de tarifas y las obligaciones de los contribuyentes. En la segunda mitad del siglo XIV, la exportación de ganado estaba gravada con la sexta vectigalia. Esta imposición fue abolida en 1399, por Martín el Humano, acaso en compensación por la franquicia del vino de Alcudia, concedida cuatro años antes ${ }^{56}$. En 1434, Alfonso el Magnánimo autorizaba a los Jurados y prohombres de Ciudadela y Mahón a imponer sisas o imposiciones in omnibus victualibus, rebus et mercibus que inhibi venduntur, ementur aut aliter contractabuntur por un período de 30 $a_{n ̃ o s}{ }^{57}$. En el período de 1476-1482 los impuestos sobre alimentos, que aparecen individualizados, gravaban la carne y el vino, el resto de impuestos alimentarios y productos estaban agrupados bajo el epígrafe de imposició ${ }^{58}$, aunque sorprende la ausencia de imposiciones sobre cereales como en Mallorca e Ibiza.

\section{Los afitons}

La primera mención sobre los afitons a impuestos indirectos se produce, en Mallorca, en 1359, conectados a la financiación de la guerra con

\footnotetext{
${ }^{55}$ J. MORELló, El mercat de les imposicions a Eivissa, cit., pp. 19-20 .

${ }^{56}$ A. ARAGÓ; R. CONDE, Llibre Vermell, cit., p. 165.

${ }^{57}$ A. ARAGÓ; R. CONDE, Llibre Vermell, cit., pp. 101 y 170.

${ }^{58} \mathrm{~F}$. SASTRE, Algunas notas sobre la situación económica, cit., p. 18.
} 
Castilla. Después, en 1376-1377, la documentación menciona de forma genérica los afitons e generalitats establecidos para financiar la cantidad votada en las Cortes Generales de aquel año. Dos de los afitons conocidos en esta fecha eran el de la molienda y el de los paños ${ }^{59}$. En cualquier caso, a estos afitons se les adjudica un carácter instrumental, sirven de base para cargar censales sobre los mismos, y no finalista, destinados a financiar directamente la cantidad votada.

En la compilación de la normativa fiscal, realizada en 1390, no hay ninguna mención a los afitons mencionados, lo cual probaría su abolición, cumplido ya su objetivo, aunque esta aserción queda pendiente de nuevas comprobaciones.

A partir de 1405, cuando todos los impuestos indirectos quedan vinculados al pago de los intereses de la deuda pública, la Universidad de Mallorca necesita el consentimiento expreso de los acreedores para financiarse a través de los afitons, ya que éstos se solapaban y regían por la misma normativa que sus matrices o imposicions majors. Los afitons se arrendaban separados de sus matrices, quedando al margen de las imposiciones consignadas. Esta era la situación de partida, porque los afitons servían de respaldo a nuevas emisiones de títulos de deuda y finalizaban integrándose en el colectivo de imposiciones consignadas ${ }^{60}$. Esto no significaba que los afitons acababan fundiéndose con sus matrices, sino que de acuerdo con su normativa seguían arrendándose por separado, sólo que ahora a beneficio exclusivo de los acreedores.

Por esta razón, la compilación de impuestos municipales, realizada en la primera mitad del siglo XV (C30) inserta, a diferencia del código de 1390, la normativa que afecta a tres afitons: molienda, carne y victigal de la mercaderia.

En la molienda se grava a panaderos y bescuyters por quartera de grano molido o quintal de harina con 9 dineros, si se trata de trigo, y 6 dineros y meaja, si se trata de mestall o mezcladizo. En cuanto a los particulares se les aplica la tarifa de 3 dineros por quartera de grano de trigo o quintal de harina ${ }^{6}$.

El "afitó" de la carne contemplaba una tarifa única de un dinero por libra, sin consideración a la calidad de la misma ${ }^{62}$. En el afitó del victigal de la mercaderia se establecía una imposición de 15 sueldos por cada paño de lana extranjero (tanto crudo como adobado ${ }^{63}$ y la importación y exportación

\footnotetext{
${ }^{59}$ ARM, AH-2170, fol. 70 r.-70 v.

${ }^{60} \mathrm{R}$. URGELL, El municipi de Mallorca en el segle XV, en La Ciutat de Mallorca, 750 anys de govern municipal, Palma de Mallorca, 2000, p. 36.

${ }^{61} \mathrm{ARM}, \mathrm{C} 30$, fol. $113 \mathrm{r}$.

62 "Un diner per liura de tota la carn qui.s vena a tall e en altra manera fos tinguda pagar imposició o siza" (ARM, C30, fol. 129 r).

${ }^{63} \mathrm{ARM}, \mathrm{C} 30$, fol. $46 \mathrm{r}$.
} 
de esclavos quedaba gravada con 100 sueldos de afitó por cada individuo, con independencia de su edad ${ }^{64}$.

El fin de la guerra civil catalana y el consecuente proceso de retrocesión de los títulos de deuda a los acreedores fue una coyuntura aprovechada para establecer nuevos afitons. En 1474, el Consell General de Mallorca aprobó el establecimiento de tres afitons: sobre el tall dels draps, victigal de la mercaderia y sobre la importación y exportación de lana. En el primer caso se trataba de un recargo de un sueldo por libra, en el segundo caso de un dinero por libra y respecto a la lana, 6 dineros por libra ${ }^{65}$. En 1487 consta el arrendamiento de dos afitons sobre la carne y tall del draps, aunque desconocemos el sistema de tarifas aplicado.

En simetría con Mallorca, J. Morelló documenta la presencia de un afitó de la carn en Ibiza, establecida en 1440. Se trataba también de una tarifa única, de dos dineros por libra de peso, sobre cualquier tipo de carne ${ }^{66}$.

Finalmente, en 1475 , en el marco de una crisis financiera de la Universidad de Menorca fueron establecidos afitons, con la finalidad de pagar deudas atrasadas ${ }^{67}$. No se concreta en la documentación la naturaleza de los mencionados afitons, aunque cabe vincularlos a las imposiciones más rentables sobre la carne, vino y paños.

\section{El Dret del General}

A raíz de la revuelta de 1450-1452, Alfonso el Magnánimo condenó a los campesinos, promotores de la misma, al pago de una indemnización por valor de 150.000 libras y a los habitantes de la capital de la isla a hacerse cargo de los gastos de las tropas enviadas para sofocar la rebelión; en este último caso, la cantidad fue establecida en 20.000 ducados.

Los habitantes del interior de Mallorca establecieron, en 1454, impuestos sobre el patrimonio (tallas) con el fin de allegar dicha cantidad, en un proceso coordinado por el Sindicato Foráneo, en tanto que los representantes de la ciudad, después de haber barajado el establecimiento de un impuesto sobre el patrimonio, optaron finalmente por establecer un impuesto extraordinario, llamado dret del General ${ }^{68}$, a recaudar entre los habitantes de la capital de la isla. Se trataba de un impuesto finalista, es decir, destinado exclusivamente al pago de los mencionados 20.000 ducados. Una vez conseguido el objetivo, el impuesto debía ser abolido. Previsiones optimistas pensaban que la cantidad se conseguiría en tres o cuatro anualidades, sin embargo el impuesto prolongó su vigencia durante catorce años, de 1454 a

\footnotetext{
64“"no feta axó, com dit és, defarència de adat ne valúa de aquells" (ARM, C30, fol. 46 v).

${ }^{65} \mathrm{R}$. URGELL, El regne de Mallorca a l'època de Joan II. La guerra civil catalana i les seves repercussions, Mallorca, 1997, p. 85.

${ }^{66} \mathrm{~J}$. MORELló, El mercat de les imposicions a Eivissa, cit., pp. 10-11.

${ }^{67} \mathrm{~F}$. SASTRE, Algunas notas sobre la situación económica, cit., pp. 39-40.

${ }^{68} \mathrm{R}$. URGELL, El Dret del General, ordenanzas e incidencias (1454-1470), "Mayurqa”, 22/2 (1989), pp. 623-632.
} 
1470. Tras una primera anualidad, en que la recaudación ascendió a 6.000 libras, en los años siguientes descendió a poco más de 2.000 libras.

El mencionado dret del General es una especie de impuesto de impuestos, en el que se reúnen dos características, la del afitó o recargo y la de una pluralidad de nuevos impuestos, unificados por el establecimiento de una tarifa única de un dinero por libra:

a) Actúa como un afitó porque grava las compraventas de productos de primera necesidad, salvo que sean para consumo propio, la importación y exportación de mercancías y la compraventa de inmuebles y establecimientos, la compraventa de rentas y las permutas.

b) Actúa como nuevo impuesto al someter a la fiscalidad el arrendamiento de inmuebles, la percepción de censales de deuda pública (el impuesto se calcula sobre los intereses anuales y afecta a todos los preceptores de censales), las herencias, las donaciones inter vivos, la venta de bienes en subasta judicial, las consignaciones, hechas por deudores a acreedores, sobre bienes o rentas propios.

Como he mencionado, el dret del General supone una breve pero reveladora experiencia fiscal, al aflorar nuevas fuentes de riqueza relacionadas con la propiedad y con la renta. Pero el hecho de incorporar estas fuentes de riqueza sólo en unas circunstancias extraordinarias nos manifiesta que se trata de un paréntesis, no de una voluntad permanente de incorporar fuentes de riqueza a la fiscalidad, que convirtieran el sistema fiscal en algo más justo.

\section{EL RENDIMIENTO DE LOS IMPUESTOS INDIRECTOS}

Las imposiciones municipales, que he mencionado en el capítulo anterior, eran alienadas mediante el sistema de arrendamiento por un año, utilizando el sistema de subasta pública.

Pero, en 1405, cuando la Universidad de Mallorca pierde el control de sus recursos fiscales indirectos, los impuestos pasan a ser arrendados y administrados por los clavarios llamados de la Consignació ${ }^{69}$. Sólo en circunstancias extraordinarias, como la suspensión de pagos de 1425, y las reformas emprendidas por Fernando el Católico permiten conocer, aunque no totalmente, la cantidad por la que eran arrendados los impuestos municipales o la cantidad ingresada con cargo a dichos impuestos ${ }^{70}$. De esta forma, del año 1425 conocemos los ingresos reales, al menos los ingresados durante esta anualidad, y de 1487 y 1491 los precios de arrendamiento obtenidos, aunque

${ }^{69}$ Hasta el año 1431, los dos clavarios eran designados por los acreedores, a partir de esta fecha sólo un de ellos, el "clavari bosser" era elegido por los mencionados y el otro por el "Consell General". En 1441 ocupaban este cargo Joan Geronés y Francesc de Comelles (ARM, EU 5, fol. 59 r.)

${ }^{70}$ Pese a las sucesivas ordenanzas que disponían la elaboración de registros de censales, de arrendamientos de imposiciones, de deudas de la Universidad con terceros, de restos de impuestos adeudados a la Universidad no se han conservado registros de arrendamientos y del rendimiento de los impuestos, salvo en las fechas indicadas de 1425 y en la época de Fernando el Católico. 
faltan algunos impuestos que, en lugar de ser arrendados, fueron gestionados directamente por la administración.

En la capital de Mallorca, todos los impuestos indirectos eran arrendados individualmente, mientras que en el interior de la isla se procedía en la misma forma respecto a la molienda, carne, vino y paños y el resto se agrupaban bajo el nombre de imposició.

En el cuadro siguiente, he tabulado todas las imposiciones que aparecen en la documentación de la época. Destaca, por supuesto, el grupo de imposiciones sobre productos de primera necesidad: Molienda, Quint del vi, ajuda de la carn. En 1425, estas tres imposiciones suman 17.632 libras, que suponen algo más del 48\% del total ingresado esta anualidad (36.455 libras, 8 sueldos, 5 dineros), porcentaje que se hubiera elevado mucho más de conocerse los datos de la molienda recaudada en el interior de la isla. En 1487, las mencionadas imposiciones, incluyendo el afitó de la carne, fueron arrendadas por un total de 21.035 libras, lo cual supuso un 59,5\% del total de los arrendamiento de aquella anualidad (36.772 libras).

En la tabla, figuran dos afitons significativos sobre la carne y sobre los paños, que en conjunto suponen algo más del 5\% de los arrendamientos realizados aquél año.Las cifras de la tabla siguiente están expresadas en libras y, mientras en los años 1403 y 1487 se trata de cifras obtenidas en los arrendamientos, en el año 1425 se refieren a ingresos reales durante la anualidad mencionada.

Imposiciones de Mallorca (1403-1487)

Abreviaturas: $1 .=$ libras; $\mathrm{s} .=$ sueldos; $\mathrm{d}$. $=$ dineros

\begin{tabular}{|l|c|l|l|}
\hline $\begin{array}{l}\text { Impuesto arren- } \\
\text { dado }\end{array}$ & $\begin{array}{l}\text { Año 1403 } \\
\text { (arrendamientos) }\end{array}$ & $\begin{array}{l}\text { 1425-1426 (ingre- } \\
\text { sos reales) }\end{array}$ & $\begin{array}{l}\mathbf{1 4 8 7} \\
\text { (arrendamientos) }\end{array}$ \\
\hline $\begin{array}{l}\text { Imposició dels en- } \\
\text { cants }\end{array}$ & 320 & $2621.2 \mathrm{s.}$ & 226 \\
\hline Cuiram adobat & 150 & $1201 ., 10 \mathrm{~s}$. & 230 \\
\hline Sisé/Quint del vi & 10.000 & $\begin{array}{l}\text { Quint del vi: } \\
10.8501 ., 8 \mathrm{~s} .\end{array}$ & Quint del vi: 7.266 \\
\hline Ajuda de la carn & & $\begin{array}{l}3.2161 ., 8 \mathrm{~s} ., 6 \mathrm{~d} . \\
\text { (ciudad) }\end{array}$ & $\begin{array}{l}4.6461 . \text { (ciudad y } \\
\text { parte foránea) }\end{array}$ \\
\hline Peix fresc e salat & 173 & 149 & 144 \\
\hline Pelliceria & 220 & $1941 ., 15 \mathrm{s.}$ & $131 ., 10 \mathrm{~s}$. \\
\hline $\begin{array}{l}\text { Vectigal de la mer- } \\
\text { caderia }\end{array}$ & & $\begin{array}{l}3.8641 ., 11 \mathrm{~s} ., 1 \\
\text { d. }\end{array}$ & 4.103 \\
\hline Vectigal de l'oli & & $1.3541 ., 15 \mathrm{~s}$ & 1.009 \\
\hline
\end{tabular}




\begin{tabular}{|c|c|c|}
\hline $\begin{array}{l}\text { Imposició bestiar } \\
\text { ciutat }\end{array}$ & 50 & 101 \\
\hline $\begin{array}{l}\text { Sagell del tall dels } \\
\text { draps }\end{array}$ & $\begin{array}{l}1.437 \text { 1., } 5 \text { s., } 11 \\
\text { d. }\end{array}$ & 3.700 \\
\hline Molitja de la ciutat & $3.5661 ., 8 \mathrm{~s}$. & 4.111 \\
\hline $\begin{array}{l}\text { Molitja (parte forá- } \\
\text { nea) }\end{array}$ & & 5.012 \\
\hline Imposició filases & 110 & 232 \\
\hline $\begin{array}{l}\text { Entrada i exida de } \\
\text { navilis }\end{array}$ & 271 1., $16 \mathrm{~s}$. & 171 \\
\hline $\begin{array}{l}\text { Imp. Lana e for- } \\
\text { matgeria }\end{array}$ & 489 & 290 \\
\hline Catius e censals & 511 1., 6 s., 8 d. & 702 \\
\hline Real per bóta & 769 1., 17 s., 4 d. & 550 \\
\hline $\begin{array}{l}\text { Imposició vi e vi- } \\
\text { nagre }\end{array}$ & $3421 ., 2$ d. & 161 \\
\hline Imposició de l'oli & 1.306 1., 8 s., 2 d. & 321 \\
\hline Blat de la pera & & 302 \\
\hline Aigua del dimarts & 67 & \\
\hline \multicolumn{3}{|l|}{ Carnsalada } \\
\hline $\begin{array}{l}\text { Imposicions part } \\
\text { forana }\end{array}$ & $\begin{array}{l}7.5221 ., 14 \text { s., } 4 \\
\text { d. }\end{array}$ & 1.512 \\
\hline Afitó de les carns & & 850 \\
\hline $\begin{array}{l}\text { Afitó del tall del } \\
\text { drat }\end{array}$ & & 1.120 \\
\hline \multirow[t]{2}{*}{ Afitó dels encants } & 11. & \\
\hline & $\begin{array}{l}\text { Total años 1425- } \\
\text { 1426: } 36.4551 ., 8 \\
\text { s., } 5 \text { d. }\end{array}$ & $\begin{array}{l}\text { Total año 1487: } \\
36.7721 \text {. }\end{array}$ \\
\hline
\end{tabular}

${ }^{71} \mathrm{G}$. MoRro, Mallorca a mitjan segle XV. El Sindicat i l'alçament forà, Mallorca, 1997, pp. 158-159. 
Las cifras de recaudaciones (no constan los arrendamientos) de Menorca se circunscriben al sexenio de 1476-1482, cuando en el curso de un contencioso con un acreedor, se procedió, en la última fecha indicada, a una peritación de los ingresos registrados en el mencionado período ${ }^{72}$. En Menorca no existía una imposición sobre los cereales, por lo que las imposiciones sobre productos de primera necesidad se circunscribían al vino y la carne, la de las compraventas, a la cisa dels draps, y la de la circulación, al vectigal; bajo el nombre de imposició se reunen las demás imposiciones aparte de las mencionadas. A partir de 1475, se introducen afitons sobre las mencionadas imposiciones, destinados, junto con una subvenció o talla, a indemnizar a los acreedores de la Universidad de Menorca.

En la tabla siguiente figuran las recaudaciones registradas entre 14761482, incluyendo las imposiciones y los afitons, expresados en libras. Para tener una idea cabal de todos los recursos fiscales, debemos añadir la subvenció o impuesto sobre el patrimonio, por importe de 500 libras anuales.

\section{Imposiciones de Menorca (1476-1482)}

\begin{tabular}{|l|l|l|l|l|l|l|l|}
\hline Año & Imposició & Carne & Vino & Draps & Victigal & afitons & TOTAL \\
\hline $1476-77$ & 993.06 .00 & 497.10 .06 & 635.01 .00 & 170.00 .00 & 261.00 .00 & 1003.06 .09 & 3.5601. \\
\hline $1477-78$ & 971.01 .00 & 496.01 .00 & 614.12 .00 & $275.18,00$ & 257.10 .00 & 1006.00 .00 & 3.6211. \\
\hline $1478-79$ & 948.01 .00 & 322.03 .00 & 667.06 .02 & 296.18 .00 & 258.06 .00 & 1020.11 .00 & 3.5121. \\
\hline $1479-80$ & 962.00 .00 & 527.01 .00 & 608.06 .00 & 286.00 .00 & 275.10 .00 & 1022.04 .04 & 3.6811. \\
\hline $1480-81$ & 1017.11 .0 & 489.00 .00 & 646.07 .00 & 343.10 .00 & 305.00 .00 & 1108.03 .00 & 3.9091. \\
\hline $1481-82$ & 1070.04 .0 & 483.08 .00 & 681.01 .06 & 341.00 .06 & 300.06 .06 & 1124.17 .04 & 4.0001. \\
\hline
\end{tabular}

Como demuestra la tabla precedente, las imposiciones sobre la carne y el vino suponían un 31, 7\% del total recaudado en 1476-1477, cifra que en el último año de la muestra desciende al $29,1 \%$. Pero lo más llamativo es el carácter crucial de los afitons que se sitúan en porcentajes como el 30,9\% del total, en 1476-1477, y el 28, $1 \%$ del total en 1481-1482. A efectos comparativos, mientras en Mallorca los afitons sobre carnes y paños se situaban en un $5 \%$ del total de los arrendamientos, en Menorca suponen casi una tercera parte de lo recaudado por el municipio.

Para el período de 1462-1474 y 1500-1510 obran datos de los arrendamientos efectuados por el municipio de Ibiza, estudiados por J. Morelló. En Ibiza, la estructura de las imposiciones es más completa que en

${ }^{72}$ F. SASTRE, Algunas notas sobre la situación económica, cit. pp. 17-25. 
Menorca. Las imposiciones sobre artículos de primera necesidad incluyen tres epígrafes ( flaqueres o panaderas, carne y vino) y las imposiciones sobre compraventas y circulación incorporan la mercadería, paños y catius o esclavos.

En la tabla siguiente expongo las cifras medianas, expresadas en libras, de arrendamientos en los dos períodos mencionados ${ }^{73}$.

Imposiciones de Ibiza (1462-1510)

\begin{tabular}{|l|l|l|l|l|l|l|l|}
\hline Periodo & $\begin{array}{l}\text { Merca- } \\
\text { dería }\end{array}$ & Vino & Carne & Paños & $\begin{array}{l}\text { flaque- } \\
\text { res }\end{array}$ & catius & Total \\
\hline $1462-64$ & 1526 & 648 & 260 & 159 & 69 & 22 & 2.6841. \\
\hline $1500-10$ & 1552 & - & 222 & 198 & 72 & 29 & $(2073)$ \\
\hline
\end{tabular}

Las cifras precedentes nos ofrecen un ligero incremento de los arrendamientos, salvo respecto a la imposición de la carne, entre 1462 y 1510. Pero lo más llamativo es el papel fundamental de la imposición sobre la mercadería, que supone el 56,8\% del total de arrendamientos en 1462-1474, desplazando de este papel a las imposiciones sobre productos de primera necesidad.

Las cifras de arrendamientos y recaudaciones de los impuestos indirectos en cada una de las islas nos proporcionan una visión objetiva de lo que representaban estos recursos, pero incompleta. El caso de Ibiza, que registra comparativamente el menor nivel de drenaje de imposiciones, resulta significativo; este municipio contaba complementariamente con una variada gama de derechos sobre la explotación de la sal cedidos, algunos ya en el siglo XIII, por los señores de la isla. En el caso de Mallorca, un impuesto directo como la gabela de la sal completaba el cuadro de ingresos fiscales del municipio. Finalmente, en Menorca, otro impuesto directo llamado la subvenció, establecido en 1475, redondeaba el bloque de recursos de este municipio.

Fecha de recepción del artículo: octubre 2007.

Fecha de aceptación y versión final: enero 2008.

${ }^{73}$ J. MORELLÓ, El mercat de les imposicions a Eivissa, cit.,pp. 20-21. 


\section{BIBLIOGRAFÍA}

ABUlafiA, D., Un emporio mediterráneo. El reino catalán de Mallorca, Barcelona, Ediciones Omega.

ARAGÓ, M.; CONDE, R., Llibre Vermell de Ciutadella, Barcelona, 1977.

CATEURA BENNÀSSER, P., La trentena esgarrifadora (Guerra i fiscalitat, el regne de Mallorca, 1330-1357), Palma, Editorial El Tall. 2000.

ÍDEM, Sociedad y sistema fiscal del reino de Mallorca (1360-1400), Palma, Editorial El Tall, 2003.

FERrer, A., Les salines $i$ la sal en el Llibre de la Cadena (1261-1696), Eivissa, Ajuntament de la ciutat d'Eivissa, 2004.

JUAN VIDAL, J. La problemática de los censales: su incidencia en las Germanías (1261-1523), "Mayurqa", 13 (1975), pp. 101-158.

LÓPEZ BONET, J.F., La revolta de 1391:efectivament, crisi social, en XIII Congreso de Historia de la Corona de Aragón, Comunicaciones I, Palma, Conselleria de Cultura, Educació i Esports, pp. 111-124.

MAYOL, A., El vi en el sistema tributari de Mallorca (segles XIV-XV), "Mayurqa", 26 (2000), pp. 161-179.

MORELló, J., El mercat de les imposicions a Eivissa: els arrendaments, a Comprar, vendre i pagar al rei (Els impostos indirectes a la Corona d'Aragó i regne de Mallorca, segles XIV-XV), Palma de Mallorca, El Tall, 2006, pp. 197-213.

ÍDEM, Mallorca y la seva dependencia financera del Principat (segles XIV-XV), "Anuario de Estudios Medievales" 33/1 (2003), pp. 115-135.

Morro, G. Mallorca a mitjan segle XV. El Sindicat $i$ l' alçament forà, Mallorca, Edicions Documenta Balear. 1997.

SAntAMARÍA, A., El reino de Mallorca en la primera mitad del siglo XV, Palma de Mallorca, 1955.

SASTRE, F., Algunas notas sobre la situación económica de las instituciones menorquinas en la primera mitas del siglo XVI, Menorca, Institut Menorquí d'Estudis, 1989.

Sevillano Colom, F., La demografía de Mallorca a través del impuesto del morabatí (siglos XIV-XVI), "BSAL", 34 (1974), pp. 233-273.

Tudela, Ll., L'origen de l'impost d'entrades $i$ exides de navilis a Ciutat de Mallorca, en Comprar, vendre i pagar al rei. Els impostos indirectes a la Corona d'Aragó i regne de Mallorca, s. XIV-XV (en prensa).

URGELL, R. El regne de Mallorca a l'època de Joan II. La guerra civil catalana i les seves repercussions, Mallorca, El Tall, 1997.

ÍDEM, El municipi de Mallorca en el segle XV, en La Ciutat de Mallorca, 750 anys de govern municipal, Palma de Mallorca, Ajuntament de Palma, Rúbrica 6.

ÍDEM, El Dret del General, ordenanzas e incidencias (1454-1470), "Mayurqa", 22/2, pp. 623-632.

\section{SIGLAS EMPLEADAS}

ACA $=$ Archivo de la Corona de Aragón.

ARM = Archivo del Reino de Mallorca.

BSAL $=$ Boletín de la Sociedad Arqueológica Luliana. 